\title{
Survival and factors affecting the outcome of synovial sarcoma in children and adolescents single institute experience
}

\author{
Enas El Nadi ${ }^{1}$, Hanafy Hafez ${ }^{2}$, Alaa Younes ${ }^{3}$, Gehad Ahmed ${ }^{4}$, Mohamed S. Zaghloul ${ }^{5}$, Hala Taha ${ }^{6}$, Naglaa ELkinaai ${ }^{6}$, \\ Maeha ELwakeel ${ }^{7}$, Salma ELmenawi ${ }^{8}$, Elham Khalid ${ }^{8}$, Sayed Fadel*2, Soha Ahmed ${ }^{9}$ \\ ${ }^{1}$ Pediatric Oncology Department, Benisuef University, Beni Suef, Egypt \\ ${ }^{2}$ Pediatric Oncology, National Cancer Institute, Cairo, Egypt \\ ${ }^{3}$ Surgical Oncology, National Cancer Institute, Cairo, Egypt \\ ${ }^{4}$ Surgery Department, Helwan University, Helwan, Egypt \\ ${ }^{5}$ Radiation Oncology, National Cancer Institute, Cairo, Egypt \\ ${ }^{6}$ Surgical Pathology, National Cancer Institute, Cairo, Egypt \\ ${ }^{7}$ Radiology, National Cancer Institute, Cairo, Egypt \\ ${ }^{8}$ Clinical Research Department, Children Cancer Hospital, Cairo, Egypt \\ ${ }^{9}$ Department of Clinical Oncology, Aswan University, CCHE, Cairo, Egypt
}

Received: February 26, 2019

DOI: $10.5430 /$ jst.v9n2p6
Accepted: April 4, 2019

Online Published: April 15, 2019

\begin{abstract}
Introduction: To check the impact of the clinical and pathologic features at diagnosis and treatment given, on the outcome of synovial sarcoma in children and adolescents.

Methods: Retrospective analysis of patients below 18 years old diagnosed by synovial sarcoma and treated at Children Cancer Hospital Egypt 57,357 (CCHE) between July 2007 and December 2016. We reviewed Clinical characteristics, pathological information, treatment modalities and survival data.

Results: We included thirty one patients with median age at diagnosis was 14.8 years. Initial surgical excision was possible in 10 patients $(58.8 \%)$ while $5(29.4 \%)$ patients underwent surgical excision after response to preoperative chemotherapy. Two patients had unresectable tumor, showed no response to chemotherapy and received radiotherapy as the only local control therapy. Adjuvant radiotherapy only was given in 2 patients and 5 patients received chemotherapy without local radiotherapy and 10 patients received both modalities. The estimated 5-year overall survival and failure free survival rates for the entire group were $84.4 \% \pm 7.2 \%$ and $63.8 \% \pm 9.7 \%$ respectively, the 5-year OS and FFS were studied in correlation to age of patient, tumor size, different pathological types, site of the lesion and methods of local control. In patients with tumor size below $5 \mathrm{~cm}$ when compared to size more than $5 \mathrm{~cm}$ with OS was $(100 \%)$ in comparison to $(79.3 \pm 9.3)$ who underwent complete surgical excision either initial or post chemotherapy as it was $66.7 \%$ versus $55.6 \%$ for those with gross or microscopic residual $(p$-value $=.38)$. Also, the 3-year failure free survival was $75 \%$ versus $56.3 \%$ for those smaller than or equal $5 \mathrm{~cm}$ and those larger than $5 \mathrm{~cm}$ respectively ( $p$-value $=.3$ ).

Conclusion: Increasing number of patients to increase sample size to assess tumor size and complete surgical excision as important prognostic factors as in our study, we found them statistically insignificant. Preoperative chemotherapy can help for delayed excision in patients presented initially with unresectable tumors.
\end{abstract}

Key Words: Synovial sarcoma, Tumor size, Surgery

*Correspondence: Sayed Fadel; Email: sayedmarwan91@yahoo.com; Address: Pediatric Oncology, National Cancer Institute, Cairo, Egypt. 


\section{INTRODUCTION}

Synovial sarcoma (SS) is a malignant soft tissue tumor. They are termed SS because of their histologic resemblance to the synovium, but they rarely involve a synovial structure and are thought to arise from pluripotent mesenchymal cells..$^{[1,2]}$ Synovial sarcoma (SS) is a rare sarcoma driven by a translocation between SS18 and SSX 1, 2, or 4, with approximately 800 to 1,000 cases a year in the United States. ${ }^{[3]}$ SS accounts for $5 \%-10 \%$ of all soft tissue sarcoma with poor prognosis. ${ }^{[4-6]}$ It occurs predominantly in the young and the middle-aged with a median (35 years). ${ }^{[7]}$ Despite the existence of histologic grading criteria based on mitotic index and tumor necrosis, most SS are considered high-grade tumors. ${ }^{[4]}$ Tumors are either monophasic (pure sarcomas), biphasic (a combination or epithelioid and sarcomatous components), or poorly differentiated. ${ }^{[3]}$ It usually occurs in the extremities but any location may be affected. Symptoms vary based on tumor location, and a slow-growing painless mass is common. It is aggressive and the development of distant metastasis and subsequent death is therefore common. Less than $10 \%$ of patients have detectable metastases at the time of diagnosis. In such cases, the lung is the most common site for metastases. Prognostic factors are tumor stage, tumor size, older age, primary tumor site and initial surgical treatment whether with adequate surgical margins or not. However, the significance of these prognostic factors is not well evaluated. ${ }^{[8]}$ Ninety percent of SS have an identifiable translocation between chromosomes 18 and $\mathrm{X}$ that results in the fusion of the SYT gene on chromosome 18 and the SSX-1 or SSX-2 gene on chromosome $\mathrm{X}^{\left[{ }^{[7,9]}\right.}$ Overall survival of patients with localized disease at first presentation ranges from $57 \%$ to $88.2 \%$ while patients with metastasis at first diagnosis is quite lower. ${ }^{[7]}$ Due to the rarity of SS, there have been no randomized trials studying the use of chemotherapy in its treatment. The current standard treatment as with other soft tissue sarcomas is wide surgical resection followed by chemotherapy with or without irradiation. ${ }^{[10,11]}$ Surgery is the basic treatment and obtaining adequate margins is its principle aim. ${ }^{[12]}$ Radiotherapy plays a role in improving local control of the tumor and, then, overall survival ${ }^{[13]}$ while the role of chemotherapy in the treatment of SS remains controversial. $^{[14]}$

The aim was to evaluate the impact of the clinical and pathologic features at diagnosis and treatment given, on the outcome of synovial sarcoma in children and adolescents.

\section{Patients And methods}

Retrospective analysis of patients below 18 years old with pathological diagnosis of synovial sarcoma and treated at Children Cancer Hospital Egypt 57,357 (CCHE) between
July 2007 and December 2016 with a median follow-up period of 20.8 months (range 3.37-52.8) months.

All patients had the full initial workup including CT imaging or MRI as local assessment of the site involved assessment of metastasis by Chest X-ray, CT chest, and bone scan. Clinical characteristics, pathological information by immunohistochemistry and genetic studies when possible were done, treatment modalities and survival data were recorded and analyzed.

\section{Pathology}

\subsection{Synovial sarcoma pathological types have been de- scribed}

In the monophasic type, there is a predominance of spindle cells, mixed with round cells; cells are arranged in fascicles with a poorly defined cytoplasm; no glandular areas are present The biphasic type has a layer of columnar epithelium in addition to spindle cells; it consists of plump, round cells and spindle-shaped fibroblasts alternating with glandular.

\subsection{Immunohistochemistry}

Translocation between chromosomes 18 and $\mathrm{X}$ that results in the fusion of the SYT gene on chromosome 18 and the SSX-1 or SSX-2 gene on chromosome X were studied.

\subsection{Treatment}

We treated patients by hospital approved protocol for nonrhabdomyosarcoma soft tissue sarcoma adopted from COGARST0332 as shown in Figure 1.

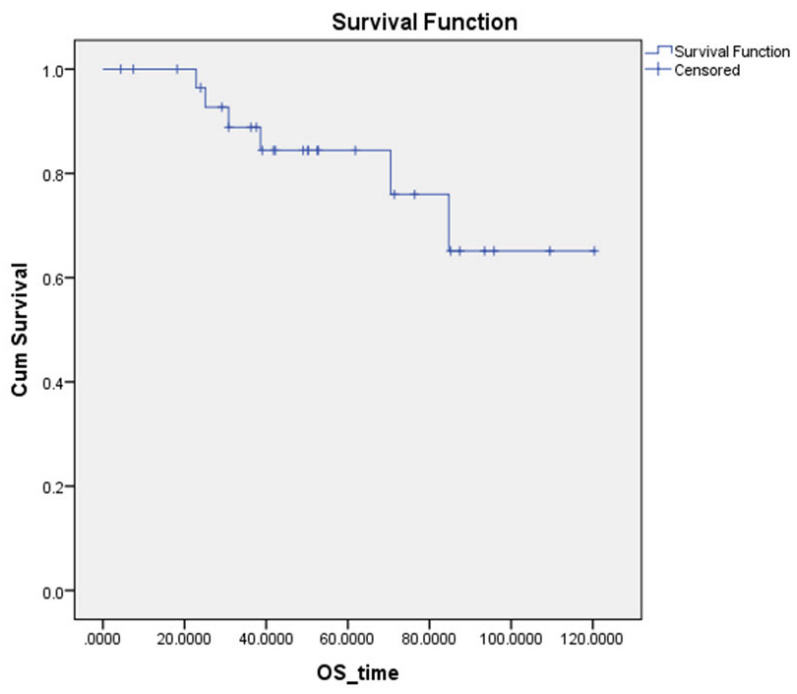

Figure 1. OS of the whole cohort. 3-Years OS $=86.5 \pm 8.9$

\subsection{Statistical analysis}

Patients' data were tabulated and processed using (SPSS) statistical package (20) for Windows. Qualitative data were 
expressed as frequency and percentage, while quantitative data were expressed as mean \pm SD. Chi-square test and Fisher Exact test were used. Statistically significant level was considered at $p \leq .05$.

Survival estimates were calculated using the Kaplan-Meier method. The differences between curves were tested for statistical significance using the log rank test. Patients without the end point events were censored on the date of the last reported contact.

Failure-free survival (FFS) was defined as the time from initial diagnosis to disease progression, recurrence, or death as a first event.

Overall survival (OS) was defined as the time from initial diagnosis to death whatever the cause is.

\section{RESUlts}

Thirty one patients were diagnosed and treated during the study period Registration date from 7-7-2007 till 31-12-2016 and patients were Followed up till 30-12-2018. Synovial sarcoma patients constituted $5.2 \%$ of soft tissue sarcoma patients. Twenty one patients were above 10 years and 10 patients were From 1 year to 10 years. Median age at diagnosis for the study cohort was 12.36 years (range 1-17.6 years) with a mean of 12.27 years. Male: female ratio was 1.7:1. The most common affected primary site was the extremities in 20 cases $(64.6 \%)$ with Lower limb mainly (14 cases). Eight cases were abdominopelvic (25.8\%), 2 cases in chest and one case head and neck.

Initial tumor size was reviewed and five patients had tumor size less than or equals $5 \mathrm{~cm}(32.3 \%)$ and 23 had tumor size more than $5 \mathrm{~cm}(74.2 \%)$ and 3 patients had unknown size: $(9.7 \%)$.

Pathological types mainly biphasic type in 25 patients and 6 patients were monophasic type. Based on pathological study (immunohistochemistry and genetic study). Genetic analysis was done in 12 cases out of the 31 , nine cases were proved to be positive to fusion of the SYT gene on chromosome 18 and 3 cases failed.

Most of the patients were categorized into intermediate risk 27 patients $(87.2 \%) 2$ patients of low and 2 patients with high risk.

Regional Lymph nodes were clinically involved in 3 cases, not involved in 22 cases and 6 cases were of unknown status. High risk patients were metastatic initially and both were presented with lung metastasis.

We treated patients according to non Rhabdomyosarcoma protocol based on CHILDREN'S ONCOLOGY GROUP 8
COG (ARST0332) Study. Patients were categorized according the protocol with two Patients (6.7\%) had Arm A, 3 patients (10\%) had Arm B, 18 patients $(56.7 \%)$ were on Arm $\mathrm{C}$ and 8 patients $(26.7 \%$ ) categorized to Arm D. Twenty cases had only surgery as local control method, 10 cases had both surgery and radiotherapy as local control method and only one had radiotherapy only. Patients who had surgery as local control method 19 cases had initial surgery and 11 cases had delayed surgery. The estimated 5-year overall survival and failure free survival rates for the entire group were $84.4 \% \pm$ $7.2 \%$ and $63.8 \% \pm 9.7 \%$ respectively. Twenty two patients were alive, 6 patients were died and 3 patients lost contact. Overall survival and disease free survival were correlated according to age, site of the tumor, method of local control, initial tumor size and pathological types. The 5 years OS to patients above 10 years was $79.3 \% \pm 9.3 \%$ in comparison to $100 \%$ in patients had age between 1 and 10 years with a $p$ value (.107) and FFS was $56.9 \% \pm 12 \%$ in above 10 years group and $80 \% \pm 12.6 \%$ in one to 10 years age group ( $p$ value was .3) (see Figures 1 and 2).

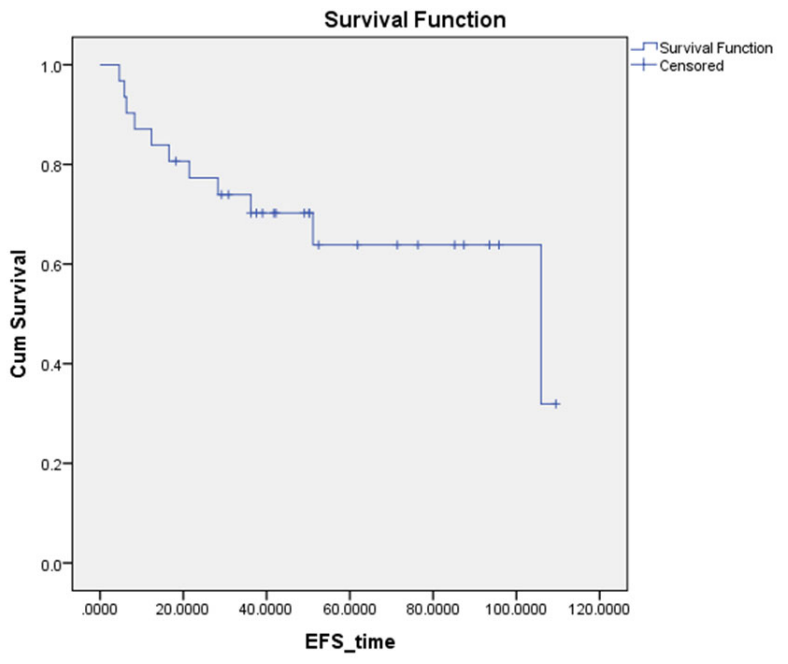

Figure 2. FFS of the whole cohort. 3-Years FFS $=48.8 \% \pm$ $14.8 \%$

For the 5-year FFS based on tumor size it was $100 \%$ versus $55.9 \% \pm 12.1 \%$ for those smaller than or equal $5 \mathrm{~cm}$ versus those larger than $5 \mathrm{~cm}$, respectively $(p$-value $=.134)$ (see Figure 3).

Twenty patients had local control of both surgery and radiotherapy and 10 cases had surgery only. OS and FFS were studied according to method of local control found to be insignificant (see Figure 4).

Patient had initial surgery were 19 cases and patients who did surgery after neoadjuvant chemotherapy were 11 cases. Eleven cases showed recurrence 6 cases had a distant recurrence, 3 cases had local recurrence and one case had both 
and another case showed regional recurrence (see Figure 5).

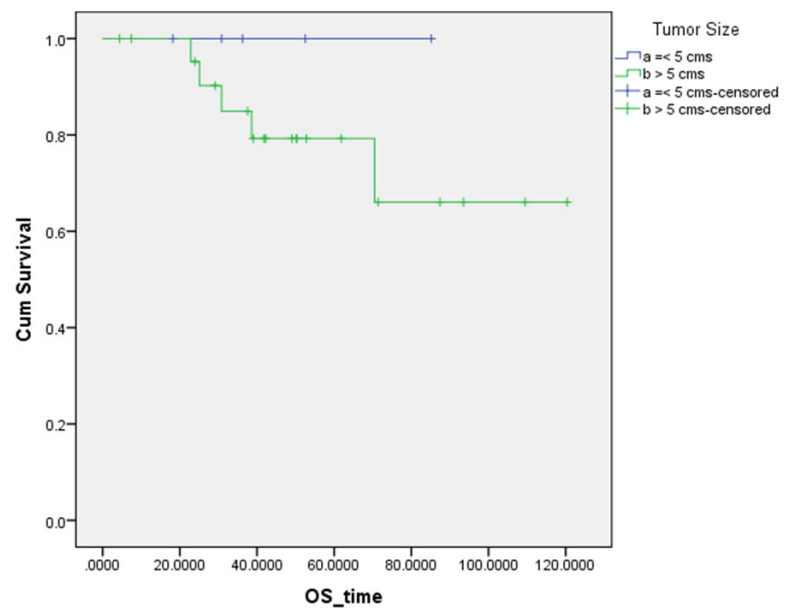

Figure 3. OS by tumor size. 3-Years-OS for those with tumor size $\leq 5 \mathrm{~cm}=100 \%$, versus $81.5 \% \pm 11.9 \%$ for those with tumor size $>5 \mathrm{~cm}(p$-value $=.38)$

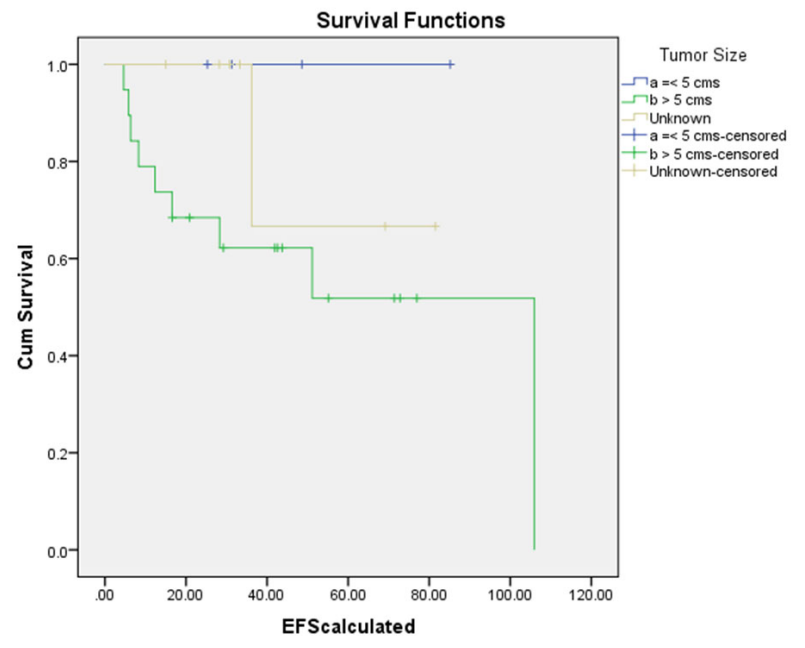

Figure 4. FFS by tumor size. 3-Years-FFS for those with tumor size $\leq 5 \mathrm{~cm}=75 \% \pm 21.7 \%$, versus $37.5 \% \pm 18.2 \%$ for those with tumor size $>5 \mathrm{~cm}(p$-value $=.29)$

\section{Discussion}

Synovial sarcoma is a clinical, morphological, and genetic well-defined entity that arises from primitive pluripotent mesenchymal cells unrelated to synovial tissue. It is a malignant soft tissue tumor accounting for $5 \%-10 \%$ of all soft tissue sarcomas ${ }^{[15]}$ this corresponded to our study it constituted $5.2 \%$ of all soft tissue sarcoma.

In this study a retrospective analysis of patients below 18 years old diagnosed by synovial sarcoma and treated at Children Cancer Hospital Egypt 57,357 (CCHE) between July 2007 and May 2016, Seventeen thirty-one patients were included in the study. In the current study median age was Published by Sciedu Press
12.36 (min age 1 -max age 17.6) with a mean age $=12.27$ years with a male: female $=2.4: 1$. In literature, it occurs predominantly in the young and the middle aged with median age 5 years. ${ }^{[8]}$ In the current study, the most common affected primary site was the extremities 20 cases about $63 \%$ of cases. Many studies indicated that synovial sarcoma usually occurs in the extremities but any site may be affected. ${ }^{[7]}$ According to Deshmukh et al, the incidence of synovial cell sarcoma has been estimated to be 2.75 per 100,000 and most cases involve the lower extremities. ${ }^{[9]}$ Previous studies have been performed to find important prognostic predictors. Results show that a younger age, a smaller tumor size, a distal limb site, and negative resection margins are correlated with improved outcomes. Adjuvant radiation therapy is also correlated with improved outcomes. ${ }^{[16]}$ Local control for patients with non-metastatic disease was excellent. The overall cancer-specific survival rate for patients with localized synovial sarcoma was $34 \%$ at 10 years. ${ }^{[17]}$

According to Lewis et al, overall survival of patients with localized disease at first presentation range from $57 \%$ to $88.2 \%$ while patients with metastasis at first diagnosis is quite lower. ${ }^{[7]}$

In the current study the estimated 5-year overall survival and failure free survival rates for the entire group were $84.4 \% \pm$ $7.2 \%$ and $63.8 \% \pm 14.9 .7 \%$ respectively. Still its five years survival by increasing follow-up survival rates may be lower.

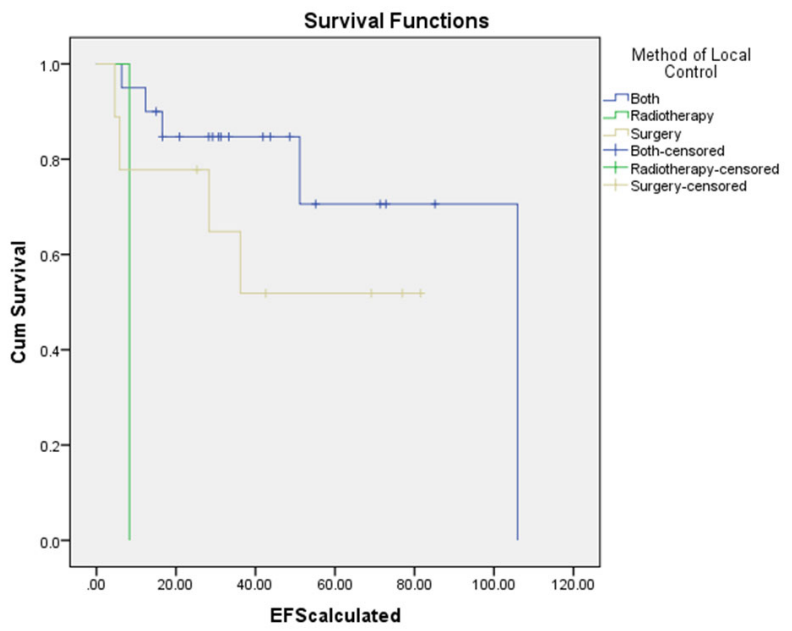

Figure 5. FFS by Method of local control. 3-Years-FFS for those who underwent surgical excision either initial or post chemotherapy $=51.9 \%$, versus $70.6 \%$ for those with both surgery and radiotherapy $(p$-value $=.033)$

In the literature, it was found hat size has a significant effect on metastasis-free, overall, and local recurrence-free. ${ }^{[16]}$ In the current study, the 5-years OS $\leq 5 \mathrm{~cm}=100 \%$ and 5 -years OS $>5 \mathrm{~cm}=79.3 \% \pm 9.3 \%(p$-value $=.33)$. The 5 -years DFS $\leq 5 \mathrm{~cm}=100 \%$ and 5 -years DFS $>5 \mathrm{~cm}=$ 
$55.9 \% \pm 12.1 \%(p$-value $=.134)$. OS and DFS were found to be insignificant may be due to small sample size.

In contrast to Kawai A, et al. 1998 who found that prognosis was associated with tumor size ${ }^{[15]}$ but in another study, Bernhard M, et al. 2011 who did not demonstrate that tumor size has an influence on the outcome of SS ( $p$-value $=.107) .{ }^{[18]}$

In the current study most of the cases were in extremities the 5-years OS and FFS of lower limb $=92.3 \% \pm 7.4 \%$ and 3 years FFS of non-extremities $=66.7 \% \pm 15.7 \%(p$-value $=$ $.522)$ in contrast to another study, patients with limb-based tumors had significantly better overall $(p$-value $=.001)$ and metastasis-free $(p$-value $=.07){ }^{[18]}$

As in other soft-tissue sarcomas, the quality of the surgical operation is crucial. Obtaining adequate surgical margins is

\section{REFERENCES}

[1] Sturgis EM, Potter BO. Sarcomas of the head and neck region. Curr Opin Oncol. 2003; 15:239-252. https://doi.org/10.1097/00 001622-200305000-00011

[2] Carillo R, Rodriguez-Peralto JL, Batsakis JG. Synovial sarcomas of the head and neck. Ann Otol Rhinol Laryngol1992; 101: 367370. PMid:1314035. https://doi.org/10.1177/0003489492 10100415

[3] Stacchiotti S, van Tine, Brian A. Synovial Sarcoma: Current Concepts and Future. Journal of Clinical Oncology. 2018; 36(2): 180-187. https://doi.org/10.1200/JC0.2017.75.1941

[4] Vancheswaran G, Behrang A, Michael JW. Sarcoma of the Head and Neck: A Single Institution Review. Vancheswaran Gopalakrishnan. 2017.

[5] Weiss SGJ, Weis SW, Goldblum JR. Malignant soft tissue tumors of uncertain type. In Enzinger FM, Weiss SW, editors, Enzinger and Weiss's Soft Tissue Tumors, 4th ed. St. Louis, CV Mosby. 2001; 1483-571.

[6] Siegel HJ, Sessions W, Casillas MJ. Synovial sarcoma: clinicopathologic features, treatment, and prognosis. Orthopedics. 2007; 30(12): 1020-5. PMid:18198773.

[7] Brennan B, Stevens M, Kelsey A, et al. Synovial sarcoma in childhood and adolescence: a retrospectiveseries of 77 patients registered by the Children's Cancer and Leukaemia Group between 1991 and 2006. Pediatr Blood Cancer. 2010; 55: 85-90. https: //doi.org/10.1002/pbc.22453

[8] Lewis JJ, Antonescu CR, Leung DH, et al. Synovial sarcoma: a multivariate analysis of prognostic factors in 112 patients with primary localized tumors of the extremity. J Clin Oncol. 2000; 18: 2087-94. PMid:10811674. https://doi.org/10.1200/JC0.2000.18.10 .2087

[9] Krieg AH, Hefti F, Speth BM, et al. Synovial sarcomas usually metastasize after $>5$ years: a multicenter retrospective analysis with minimum follow-up of 10 years for survivors. Ann Oncol. 2011; 22: 458-67. PMid:20716627. https://doi.org/10.1093/annonc/m dq394

[10] Kawai A, Woodruff J, Healey JH, et al. SYT-SSX gene fusion as a determinant of morphology and prognosis in synovial sarcoma. N Engl J Med. 1998; 338: 153-160. PMid:9428816. https : //doi.org/10.1056/NEJM199801153380303 essential to gain tumor control, and is strongly influenced by the type of healthy tissue surrounding the tumor. ${ }^{[11,18]}$ This is supported by our results, which showed that patients with a primary wide resection had a better outcome the 3-years FFS for those who underwent complete surgical excision either initial or post chemotherapy $66.7 \% \pm 19.2 \%$ and 3 -years FFS for those with gross or microscopic residual $=55.6 \% \pm$ $16.6 \%(p$-value $=.38)$.

\section{Conclusion}

Increasing number of patients to increase sample size to assess tumor size and complete surgical excision as important prognostic factors as in our study they were found to be statistically insignificant. Preoperative chemotherapy can help for delayed excision in patients presented initially with unresectable tumors.
[11] Sakabe T, Murata H, Konishi E, et al. Evaluation of clinical outcomes and prognostic factors for synovial sarcoma arising from the extremities. Med Sci Monit. 2008; 14(6): CR305-CR310. PMid:18509273.

[12] Mendenhall WM, Indelicato DJ, Scarborough MT, et al. The management of adult soft tissue sarcomas. Am J Clin Oncol. 2009; 32(4): 436-442. PMid:19657238. https://doi.org/10.1097/COC.0b 013e318173a54f

[13] Bergh P, Meis-Kindblom JM, Gherlinzoni F, et al. Synovial sarcoma: identification of low and high risk groups. Cancer. 1999; 85(12): 2596-2607. https://doi.org/10.1002/(SICI) 1097-0142 (19 990615) $85: 12<2596:$ : AID-CNCR16>3.0.CO;2-K

[14] Goodlad JR, Fletcher CD, Smith MA. Surgical resection of primary soft-tissue sarcoma. Incidence of residual tumour in 95 patients needing re-excision after local resection. J Bone Joint Surg Br. 1996; 78(4): 658-661. https://doi.org/10.1302/0301-620X.78B4 .0780658

[15] Pappo AS, Fontanesi J, Luo X, et al. Synovial sarcoma in children and adolescents: the St Jude Children's Research Hospital experience. J Clin Oncol. 1994 Nov; 12(11): 2360-2366. PMid:7964951. https://doi.org/10.1200/JC0.1994.12.11.2360

[16] Wisanuyotin T, Radapat K, Sirichativapee W, et al. Prognostic factors and clinical outcomes in synovial sarcoma of the extremities. Asia Pac J Clin Oncol. 2013 Mar; 9(1): 80-5. PMid:22898085. https://doi.org/10.1111/j.1743-7563.2012.01563.x

[17] Singer S, Baldinj EH, Demetri GD, et al. Synovial sarcoma: prognostic significance of tumor size, margin of resection, and mitotic activity for survival. J Clin Oncol. 1996 Apr; 14(4): 1201-8. PMid:8648375. https://doi.org/10.1200/JC0.1996.14.4.1201

[18] Okcu MF, Munsell M, Treuner J, et al. Synovial sarcoma of childhood and adolescence: a multicenter, multivariate analysis of outcome. J Clin Oncol. 2003 Apr; 21(8): 1602-11. PMid:12697886. https://doi.org/10.1200/JC0.2003.07.008

[19] Speth BM, Krieg AH, Kaelin A, et al. Synovial sarcoma in patients under 20 years of age: a multicenter study with a minimum follow-up of 10 years. J Child Orthop. 2011 Oct; 5(5): 335-342. PMid:23024724. https://doi.org/10.1007/s11832-011-0360-4

[20] Brecht IB, Ferrari A, Int-Veen C, et al. Grossly-resected synovial sarcoma treated by the German and Italian Pediatric Soft Tissue Sarcoma Cooperative Groups: discussion on the role of adjuvant therapies. Pediatr Blood Cancer. 2006 Jan; 46(1): 11-7. PMid:16292743. https://doi.org/10.1002/pbc. 20502

ISSN 1925-4067 E-ISSN 1925-4075 